(C) 2021 American Psychological Association. This paper is not the copy of record and may not exactly replicate the authoritative document published in the APA journal. Please do not copy or cite without author's permission. The final article is available, upon publication, at: https://doi.org/10.1037/dheoooo380

\title{
Addressing Race and Diversity in Graduate Education: Practices from Student
} Activism

Wendy Chu, Mackenzie J. Hart, Kristin N. Kirchner, Mariajosé J. Paton, and Conner J. Black Department of Psychology, University of South Carolina

\section{Author Note}

Wendy Chu, https://orcid.org/oooo-0001-6596-5987

Mackenzie J. Hart, https://orcid.org/0000-0002-3161-4254

Kristin N. Kirchner, https://orcid.org/0000-0002-5160-5195

Mariajosé J. Paton, https://orcid.org/0000-0002-7849-1394

Conner J. Black, https://orcid.org/0000-0002-9596-5790

The authors have no known conflicts of interest to disclose. Authorship was determined by contributions to the project and manuscript. When this manuscript was drafted, one author selfidentified as an Asian American woman, one author self-identified as a white Latinx woman, two self-identified as white women, and one author self-identified as a white man. One author (K.N.K.) is supported in part by Grant Number T32-GMo81740 from NIH-NIGMS. We also intentionally use a lowercase ' $w$ ' when referring to white as an active stance against white supremacy. Correspondence concerning this article should be addressed to Wendy Chu, wchu@email.sc.edu. 


\begin{abstract}
This practice brief presents the work of doctoral students who aimed to reform the graduate experience in their department to support racially minoritized students. Drawing from community organization and organizational change theories, we describe how we fostered community dialogue and crafted a demand letter to communicate students' needs and recommendations for change. We also discuss implications related to accountability, implementation, and overcoming institutional pushback. By centering students' voices, this practice brief provides a guiding framework for graduate students to engage in activism that promotes institutional change to foster a more racially inclusive environment for students. Keywords: race, diversity, student activism, graduate education
\end{abstract}




\section{Addressing Race and Diversity in Graduate Education: Practices from Student}

\section{Activism}

Though academic exclusion and marginalization occur in many intersecting domains (e.g., based on class, disability, sexual orientation, and more), injustices due to racial and ethnic identities have received attention for decades (Arday \& Mirza, 2018). Data from the National Center for Education Statistics reveal that, though there has been racial diversification and increases in enrollment in U.S. postsecondary education, graduation rates and educational outcomes for many minoritized racial groups are consistently lower than those of non-Hispanic white groups (de Brey et al., 2019). Despite greater opportunities for minoritized groups in higher education, there are still barriers within institutions that make higher education an inaccessible and excluding environment for racially minoritized students.

Graduate programs have made considerably less progress in racial diversity, equity, and inclusion (DEI) compared to undergraduate programs (de Brey et al., 2019). Particularly, students of color have characterized their experiences in graduate school by the lack of meaningful and reciprocally trusting mentorship, belongingness and social integration, and mental health supports (Brunsma et al., 2017; Fosnacht \& Calderone, 2020; Truong et al., 2016). These reports are explained in part by the large disparities in racial representation among faculty and students. Further, they could be explained by a lack of awareness or acknowledgment of the issues students face surrounding DEI, and by a lack of institutional mechanisms and programming that explicitly support students of color (Chen et al., 2020; Harris \& Lee, 2018).

Previous work has demonstrated the value of student-led initiatives and activism in raising awareness, combating inequities, and effecting reform in higher education (Jacoby, 2017; Lantz et al., 2016). Students at all levels of postsecondary education have organized discussions about the importance of anti-racist practices and the prevalence of racial discrimination on campus and have served as "political actors" by advocating for institutional 
change through collective action (e.g., through protests and demanding administrative and pedagogical reforms; Morgan et al., 2021). Additionally, student activism - when in collaboration with faculty and in contexts that value such work - can shape student development as future leaders and change academic culture, further illustrating the benefits of activism (Kezar, 2010).

Despite extant practices and research that support student activism, certain aspects of higher education, including causes surrounding racial DEI, continually dismiss students' efforts and/or ignore students' perspectives, thereby creating hurdles for student activists to overcome (Elliott et al., 2013; Long \& Mejia, 2016). Many of these instances can be attributed to institutional barriers that are rampant at predominantly white institutions, such as the acceptability and frequency of racial discrimination, including microaggressions, (Kornbluh et al., 2021), inequities in racially minoritized faculty and student retainment (Griffin, 2020), and administrators' views towards diversity and leadership styles (Adserias et al., 2017).

Given that student voices are essential for long-standing educational reform, this practice brief aims to empower graduate students who seek to engage in student activism by providing actionable suggestions for demanding institutional change to expand and strengthen racial DEI initiatives (i.e., ending discriminatory practices while enacting socially progressive change). To this end, we (five doctoral students in psychology) describe our efforts organizing a student group, interfacing with administrators and faculty, and formally calling for departmental reforms. We discuss real-world factors and previous research on student activism and community change that informed our advocacy decisions, as well as lessons learned from our endeavors.

\section{Context}

Our university is a large public university in the Southeastern United States. Historically and currently as of the 2020-2021 academic year when this manuscript was prepared, our department has exhibited challenges with recruiting and retaining racially minoritized graduate 
students and faculty, with $16.9 \%$ of students and approximately $20.0 \%$ of faculty from racially minoritized backgrounds, compared to the $36.3 \%$ racial minority population in our state (U.S. Census Bureau, 2019). Additionally, a recent graduate student survey within our department revealed that a negative perceived climate (e.g., non-collegial interactions), perceived lack of commitment to support racially minoritized students and faculty, and poor student mental health (e.g., high rates of depression) were pervasive. Coupled with the socio-political climate at the time (e.g., increased coverage of racist events, nationwide protests), the need for efforts to promote the well-being of racially minoritized students was needed (Brunsma et al., 2017; Petridis, 2015). The current paper presents guiding principles and actions that inform efforts to address race and diversity issues in graduate education, drawing from our context as a case illustration. Acknowledging differences across universities and departments, we hope that in highlighting broad principles and offering several potential actions, other graduate students can utilize these points in their activism efforts while tailoring to their specific context and needs.

\section{Theoretical Perspectives}

We leveraged perspectives from community organization and organizational change theories to inform our work. Community organization refers to "the process of bringing about and maintaining a progressively more effective adjustment between social welfare resources and social welfare needs" (Ross \& Lappin, 1955). Community organization can encompass a variety of approaches, each with its own objectives and methods. The specific approach, for example, emphasizes targeted reform to address a particular need, and the process approach emphasizes a cooperative undertaking in which all members of a community are involved (Ross \& Lappin, 1955). In the wake of civil unrest against systemic racism, particularly against Black communities in the United States, and the call to dismantle white supremacy and anti-Black racism in academia, we were galvanized into collective action and used both approaches to address the need for racial equity in our department.

Organizational change theory includes setting a goal, assessing context and conditions, 
selecting a strategy, implementing tactics and methods, and evaluating outcomes to yield change (Packard, 2013). Organizational change underscores the importance of a coordinated system in which resources and knowledge inform processes. Therefore, its tenets elevate the effectiveness and efficiency of student activism efforts. Moreover, anchoring to this system allows individuals to revisit steps or processes as student needs change, creating an adaptable system that withstands rapidly changing environments such as higher education. Given our training in and orientation to systems-level change, we used principles of community organization and organizational change to engage in community dialogue, make strategic plans, and leverage implementation tactics with the goal of promoting racial equity within our department. These theories provide a useful framework for graduate students serving as grassroots organizers and leaders to enact DEI change within their institutions.

\section{Guiding Principles and Actions}

Drawing inspiration from scholars who have described social change efforts in academic spaces (e.g., Witenstein \& Niese, 2019), we similarly organize our practice brief according to guiding principles and corresponding example actions (see Table 1). These guiding principles reflect broad constructs and values that we believe contribute to the success of student activism efforts, and these example actions offer concrete steps that students can take. To begin the initiative, a small group of students with existing student leadership positions, commitment to DEI, and expertise in organizational planning met to discuss objectives. The main goals identified through this initial discussion were to elevate graduate students' voices on racism and discrimination within our department, identify demands and recommendations based on students' experiences and perspectives, and enact lasting change at the departmental level through a partnership with faculty and administrators. These early efforts were primarily student-driven, and others were strategically invited at a later stage as outlined below.

\section{Community Dialogue}

Community dialogue, or intergroup dialogue, is a common practice in higher education 
for fostering discussion and change among students (Zúñiga et al., 2007). Community dialogue aims to develop critical consciousness through reflections about systems of power, and to develop a shared common ground to strengthen a community's capacity for social action (Zúñiga et al., 2007). Dialogue may include reflection of how certain communities benefit from privilege, opportunities for individuals to speak openly about navigating disempowering spaces, and brainstorming potential strategies for improvement. In higher education, community dialogue often takes the form of town hall style meetings where students share feedback, input, and ideas among each other, and oftentimes with faculty and staff in presence, in a safe environment (Bemak et al., 2011; Green et al., 2008).

As the visibility of anti-Black racism in the United States and calls to dismantle white supremacy increased in predominantly white spaces such as academia (Martinez, 2020), we planned a graduate student-only town hall style meeting to listen to concerns, share experiences, and brainstorm ideas on how to reform the department and student experience to align with the promotion of social justice around race and diversity. Students who could not attend the meeting were encouraged to share their thoughts anonymously on an online, encrypted survey. Faculty and staff were intentionally not invited to this town hall given the potential power dynamics that may discourage open community dialogue. This meeting was held virtually on a password-required and waiting room-enabled platform to instill a sense of safety. This meeting served as a counterspace (Case \& Hunter, 2012) to help students process their concerns regarding race and diversity issues and was an important first step in strategic planning.

\section{Strategic Planning}

Strategic planning is a crucial step to implementing change, especially in large organizations such as an academic institution (Bresser \& Bishop, 1983). Well-planned initiatives simplify many ideas into categories, organize concerns, and communicate needs as clear actionable messages (Dutton \& Duncan, 1987). Methods of communicating calls for change 
include student petitions and protests. Another method is a demand letter. Demand letters are commonly used in academia as formal documents that call upon an audience to enact change on a topic, such as race and diversity (e.g., Michaels, 2020). One advantage of demand letters is that they ensure many voices are represented in a format that can be quickly and easily disseminated.

The success of a demand letter depends on many factors, including how institutions perceive and respond to the message conveyed through the letter and how messages are communicated. While we believe that institutions must take the lead on planning change to support racially minoritized students, student-written demand letters can provide rapid communication that is both specific and timely to institutional leaders as they consider change. Messages that are professionally written and clearly outlined can increase their intended impact. Thus, the experiences and perspectives of students gathered through community dialogue can be transformed into action items, which can then be assembled into logical categories in a demand letter. In addition, it is strategic to incorporate as many voices as possible into a demand letter so institutions can perceive the urgency of the message as demonstrated by community support. Demand letters can garner such support through the form of signatures. Websites such as Change.org and open documents (e.g., Google Documents) are feasible and familiar options to students for quickly gathering signatures.

Following our town hall, we developed a demand letter in which we called for changes such as requiring faculty attendance at a university diversity training, diversifying course syllabi, and implementing clinical skills workshops that focus on cultural competence. These action items came directly from graduate students and alumni or were inspired from our community dialogue. We intentionally organized our letter by categories that were associated with certain formed groups within our department (e.g., clinical training concerns directed to clinical faculty; department concerns directed to department leadership) to identify groups of individuals who could oversee and collaborate with students in enacting change. Moreover, we leveraged 
empirical literature and references from other institutions to provide exemplary actions and increase the impact of our messages. Our process of strategic planning to address race and diversity in our department involved the collaborative input and support of current students and alumni to craft, edit, and sign an organized demand letter. This demand letter can be publicly accessed here: https://osf.io/zxj36/.

\section{Implementation Tactics}

The use of several tactics is key to ensuring that organizational change and strategic planning are successfully implemented (Packard, 2013). Establishing a team of students recognized as peer leaders can immensely support the change plan. Ideally, this team is representative of the student body (e.g., from different concentrations, programs, or backgrounds). Obtaining buy-in and fostering a positive relationship with higher levels of management (e.g., department chairs, deans) are tactics that increase the likelihood that student activism is recognized, valued, and supported. These connections are particularly important, as those in positions of power in higher education can have a large influence on the direction and magnitude of change impacting students. Other valuable tactics include involving multiple groups of stakeholders and leveraging organizational capacity to have a more widespread workforce. For example, a diversity committee is a group already committed to advancing DEI and who can leverage their power across a program or department to promote student activism. Lastly, though underutilized, two components that are imperative to change are monitoring its implementation and evaluating progress to measure the impact of change. For example, one might administer a measure at the beginning and end of an academic year to measure specific outcomes, such as students' perception of department climate around diversity or provided support. Documenting progress and collecting measurable data are also important ways to inform any adaptations and modifications to plans.

Our department has several existing structures that aided in the practice of these tactics. We have a graduate student advocacy group that frequently collaborates with departmental 
leadership on various student initiatives, whose leadership board comprised of the authors at the time this article was prepared. We also have a DEI committee in our department that is committed to supporting racially minoritized graduate students. Similarly, our department has had a long-standing orientation to using data to inform and guide action, and thus faculty and administrators were receptive to ideas of collecting and receiving data from students. The data we presented were the collated actions items derived from the perspectives of dozens of students and alumni in our demand letter. While we recognize that these structures in our department have helped us make significant progress in our student activism efforts, we assert that these tactics can be adapted and applied to many graduate departments and programs.

\section{Anticipating and Navigating Challenges}

With any demand for change, obstacles and resistance should be anticipated. One potential challenge is critique, or even direct opposition, from those with more power than students. Similar to what is described above, organization and planning can facilitate addressing specific points of critique that are likely to surface. For example, if critique is anticipated from faculty, student leaders may proactively organize and present the petition for change in a formal, live setting, such as a faculty meeting or small group of faculty, which would allow for an open conversation and for the opportunity to provide clarification to any questions or concerns raised. Moreover, this would allow students and faculty to collaboratively brainstorm potential solutions to these points if there is direct opposition to a proposed change.

We also recognize that a common challenge or barrier to student activism is fear of retribution. These experiences are valid especially given that participating in an initiative that is negatively perceived by individuals who hold and control student power (e.g., faculty and advisors) can result in implications on student success (e.g., being perceived as a "troublemaker" and thus being withheld from certain opportunities). There are many ways of protecting students while pursuing student activism efforts. Anonymous student feedback and participation is essential. For example, we distributed a feedback form where students could 
share anonymous input throughout our efforts. Additionally, student representatives can serve as leaders of the general student body, protecting students who hold less power, and establish partnerships with faculty and staff to ensure there will be no retribution of any sorts for students.

Another potential challenge is time and resource demand. While recognizing that enacting institutional change requires effort, this can be lessened by utilizing existing resources at the university level, or other resources for guidance and help. For example, many institutions have made guidelines on developing inclusive syllabi or equitable recruitment practices publicly available. Sometimes, a professional consultant from an outside organization may be helpful in such cases where burden is a significant barrier. Another anticipated barrier might be that student initiatives are forgotten or discarded after a short period of time. Forming a committee that can regularly convene, make gradual progress on joint work, and keep those involved accountable will likely help any effort be successful. Indeed, partnering and sharing duties with faculty, such as in the context of a formal committee, may make graduate student activism more sustainable and serve to maintain accountability for institutional leaders (Cho, 2018).

Finally, we acknowledge that academic institutions were originally built for and to serve white individuals, creating a long history of institutional racism, whiteness, and inaccessibility and exclusion of marginalized people especially people of color (Museus et al., 2015).

Reconciling with this history to reshape how organizations and institutions respond to student activism is critical for instilling change to promote racial equity.

\section{Conclusion}

As graduate programs continue to recruit students from racially minoritized backgrounds, it is necessary to proactively address race and diversity problems in the academe. Students should feel safe to label the problems they experience and to demand solutions that address them. Thus, we call for institutions to support students advocating for change in their own programs. We have described three guiding principles and provide example action items 
that students can engage in to optimize the success of their activism. First, community dialogue can be used to provide a space that ensures student voices are heard. Second, strategic planning is needed for any call for change to be organized and successful. Third, implementation tactics are important to make sure that the efforts result in meaningful and sustainable changes. These guiding principles have allowed for change within our department by increasing dialogue among students and faculty working towards a more equitable educational environment. Despite these initial accomplishments, ongoing collective work including administrators and faculty is needed to calcify change within institutions. In sum, we hope this practice brief empowers students to engage in efforts to make higher education an environment where all students, especially racially minoritized students, feel safe and are supported. 


\section{References}

Adserias, R. P., Charleston, L. J., \& Jackson, J. F. L. (2017). What style of leadership is best suited to direct organizational change to fuel institutional diversity in higher education? Race Ethnicity and Education, 20(3), 315-331. https://doi.org/fgc5

Afolabi, T., Borowsky, H. M., Cordero, D. M., Paul, D. W., Jr, Said, J. T., Sandoval, R. S., Davis, D., Ölveczky, D., \& Chatterjee, A. (2021). Student-led efforts to advance anti-racist medical education. Academic Medicine, 96(6), 802-807. https://doi.org/gkvm5h

Arday, J., \& Safia, M. H. (2018). Dismantling race in Higher Education: Racism, whiteness and decolonising the Academy. Springer.

Bemak, F., Talleyrand, R. M., Jones, H., \& Daquin, J. (2011). Implementing multicultural social justice strategies in counselor education training programs. Journal for Social Action in Counseling \& Psychology, 3(1), 29-43. https://doi.org/gh3fs6

Bresser, R. K., \& Bishop, R. C. (1983). Dysfunctional effects of formal planning: Two theoretical explanations. Academy of Management Review, 8(4), 588-599. https://doi.org/ckzdd3

Brunsma, D. L., Embrick, D. G., \& Shin, J. H. (2017). Graduate students of color: Race, racism, and mentoring in the white waters of academia. Sociology of Race and Ethnicity, 3(1), 113. https://doi.org/gftvz4

Case, A. D., \& Hunter, C. D. (2012). Counterspaces: A unit of analysis for understanding the role of settings in marginalized individuals' adaptive responses to oppression. American Journal of Community Psychology, 5o(1-2), 257-270. https://doi.org/f37h8j

Chen, J. A., Tutwiler, M. S., \& Jackson, J. F. L. (2020). Mixed-reality simulations to build capacity for advocating for diversity, equity, and inclusion in the geosciences. Journal of Diversity in Higher Education. Advance online publication. https://doi.org/g24g

Cho, K. S. (2018). The perception of progress: Conceptualizing institutional response to student protests and activism. NEA Higher Education Journal: Thought and Action, 34(1), 8195. 
de Brey, C., Musu, L., McFarland, J., Wilkinson-Flicker, S., Diliberti, M., Zhang, A., Branstetter, C., \& Wang, X. (2019). Status and Trends in the Education of Racial and Ethnic Groups 2018 (NCES 2019-038). U.S. Department of Education. Washington, DC: National Center for Education Statistics.

Dutton, J. E., \& Duncan, R. B. (1987). The influence of the strategic planning process on strategic change. Strategic Management Journal, 8(2), 103-116. https://doi.org/df67sr

Elliott, C. M., Stransky, O., Negron, R., Bowlby, M., Lickiss, J., Dutt, D., Dasgupta, N., \& Barbosa, P. (2013). Institutional barriers to diversity change work in higher education. SAGE Open, 3(2). https://doi.org/g24h

Fosnacht, K., \& Calderone, S. (2020). Who do students trust? An exploratory analysis of undergraduates' social trust. Presented at the 2020 Annual Meeting of the Association for the Study of Higher Education.

Green, E. J., McCollum, V. C., \& Hays, D. G. (2008). Teaching advocacy counseling within a social justice framework: Implications for school counselors and educators. Journal for Social Action in Counseling \& Psychology, 1(2), 14-30. https://doi.org/gh3fs8

Griffin, K. A. (2020). Looking beyond the pipeline: Institutional barriers, strategies, and benefits to increasing the representation of women and men of color in the professoriate. In L. Perna (Ed.), Higher education: Handbook of theory and research (vol. 35). Switzerland: Springer.

Harris, T. M., \& Lee, C. N. (2018). Advocate-mentoring: A communicative response to diversity in higher education. Communication Education, 68(1), 103-113. https://doi.org/f3hf

Hoffman, G. D., \& Mitchell, T. D. (2016). Making diversity "everyone's business": A discourse analysis of institutional responses to student activism for equity and inclusion. Journal of Diversity in Higher Education, 9(3), 277-289. https://doi.org/f84zq.5

Jacoby, B. (2017). The new student activism: Supporting students as agents of social change. Journal of College and Character, 18(1), 1-8. https://doi.org/g24j 
Kezar, A. (2010). Faculty and staff partnering with student activists: Unexplored terrains of interaction and development. Journal of College Student Development, 51(5), 451-480. https://doi.org/db5phc

Kornbluh, M., Johnson, L., \& Hart, M. (2021). Shards from the glass ceiling: Deconstructing marginalizing systems in relation to critical consciousness development. American Journal of Community Psychology, 68(1-2), 187-201. https://doi.org/gmc6p4

Lantz, M. M., Fix, R. L., Davis, B. L., Harrison, L. N., Oliver, A., Crowell, C., Mitchell, A. M., \& García, J. J. (2016). Grad students talk: Development and process of a student-led social justice initiative. Journal of Diversity in Higher Education, 9(3), 290-306. https://doi.org/f84xt6

Long, L., \& Mejia, J. A. (2016). Conversations about diversity: Institutional barriers for underrepresented engineering students. Journal of Engineering Education, 105(2), 211218. https://doi.org/g24k

Lopez, G. E., \& Zúñiga, X. (2010). Intergroup dialogue and democratic practice in higher education. New Directions for Higher Education, 2O1O(152), 35-42. https://doi.org/fnszkp

Martinez, R. (2020, May 28). Sent this email to my department today. We have to disrupt silence. https://twitter.com/1solbro/status/1266057633938669569

Michaels, M. (2020, July 7). In open letter, faculty call for anti-racist action, diversity in decision-making. The Daily Princetonian. https://www.dailyprincetonian.com/article/2020/07/princeton-350-faculty-anti-racistcurriculum-committees

Morgan, D. L., Zilvinskis, J., \& Dugan, B. J. (2021). Opening the activism and postsecondary education black box: Relating high-impact practices and student identity with activist behaviors. Journal of Political Science Education, 17(1), 55-78. https://doi.org/g24n

Museus, S. D., Ledesma, M. C., \& Parker, T. L. (2015). Systemic racism in higher education. The 
ASHE Higher Education Report, 42(1), 49-71.

Packard, T. (2013). Organizational change: A conceptual framework to advance the evidence base. Journal of Human Behavior in the Social Environment, 23(1), 75-90. https://doi.org/g24p

Petridis, H. L. (2015). Thriving in graduate school: The role of department climate, studentfaculty interaction, family-friend support, and a psychological sense of community. Azusa Pacific University.

Ross, M. G., \& Lappin, B. W. (1955). Community organization: Theory and principles. New York: Harper.

Truong, K. A., Museus, S. D., \& McGuire, K. M. (2016). Vicarious racism: A qualitative analysis of experiences with secondhand racism in graduate education. International Journal of Qualitative Studies in Education, 29(2), 224-247. https://doi.org/ggdf4j

U.S. Census Bureau. (2019). QuickFacts South Carolina. https://www.census.gov/quickfacts/SC

Witenstein, M. A., \& Niese, M. (2019). Applying guiding principles to resist erasure of immigrant community college students in an ever-changing climate through a critical theory of love. Journal of Applied Research in the Community College, 26(2), 1-10.

Young, K., Anderson, M., \& Stewart, S. (2015). Hierarchical microaggressions in higher education. Journal of Diversity in Higher Education, 8(1), 61-71. https://doi.org/f642r9

Zúñiga, X., Nagda, B. A., Chesler, M., \& Cytron-Walker, A. (2007). Intergroup dialogues in higher education: Meaningful learning about social justice. ASHE-ERIC Report Series, 32(4). San Francisco, CA: Jossey-Bass. 


\section{Table 1}

Guiding Principles and Actions for Addressing Race and Diversity in Graduate Education

\begin{tabular}{|c|c|}
\hline Guiding Principle & Example Actions \\
\hline Community Dialogue & $\begin{array}{l}\text { Create spaces where students can openly share their perspectives } \\
\text { and process their experiences } \\
\text { Use several and different methods including confidential and } \\
\text { anonymous outlets to solicit student perspectives } \\
\text { Foster discussions centered on students' experiences with the aim } \\
\text { of using a collective student voice to demand action }\end{array}$ \\
\hline Strategic Planning & $\begin{array}{l}\text { Formalize requests for change into a written demand letter or } \\
\text { petition } \\
\text { Organize requests for change into categories grouped by topic } \\
\text { relevance or intended audience } \\
\text { Garner support from the community in the form of signatures or } \\
\text { letters of support to demonstrate urgency and importance }\end{array}$ \\
\hline Implementation Tactics & $\begin{array}{l}\text { Establish a team of representative student leaders with clearly } \\
\text { defined roles who can oversee activism efforts } \\
\text { Leverage multiple stakeholders and organizational capacity to } \\
\text { increase dissemination and sustainability of change efforts } \\
\text { Collect outcomes data to measure impact of change and to } \\
\text { determine necessary adaptations or modifications to efforts }\end{array}$ \\
\hline
\end{tabular}

